\title{
Is the omega sign a reliable landmark for the neurosurgical team? An anatomical study about the central sulcus region
}

\author{
O sinal do ômega é um reparo anatômico confiável para a equipe neurocirúrgica? Estudo \\ anatômico sobre a regiāo do sulco central
}

Thiago Rodrigues ${ }^{1}$, Mariana Rodrigues², Daniel Paz', Marcos Devanir Costaํ.,Bruno Santos ${ }^{3}$, Vinicius Braga ${ }^{3}$, Manoel de Paiva Neto ${ }^{4}$, Ricardo Centeno', Sergio Cavalheiro', Feres Chaddad-Neto ${ }^{3,5}$

\begin{abstract}
The central sulcus region is an eloquent area situated between the frontal and parietal lobes. During neurosurgical procedures, it is sometimes difficult to understand the cortical anatomy of this region. Objective: Find alternative ways to anatomically navigate in this region during neurosurgical procedures. Method: We analyzed eighty two human hemispheres using a surgical microscope and completed a review of the literature about central sulcus region. Results: In 68/82 hemispheres, the central sulcus did not reach the posterior ramus of the lateral sulcus. A knob on the second curve of the precentral gyrus was reliably identified in only $64 / 82$ hemispheres. Conclusion: The morphometric data presented in this article can be useful as supplementary method to identify the central sulcus region landmarks.
\end{abstract}

Keywords: omega sign, central sulcus, anatomy, primary motor cortex.

\section{RESUMO}

A região do sulco central é uma área eloquente posicionada entre os lobos frontal e parietal. Durante procedimentos neurocirúrgicos, em algumas ocasiões, torna-se difícil compreender a anatomia cortical desta região. Objetivo: Encontrar métodos alternativos para uma navegaçāo anatômica desta regiāo durante procedimentos neurocirúrgicos. Método: Analisamos oitenta e dois hemisférios humanos usando um microscópio cirúrgico, além de fazer uma revisão da literatura. Resultados: Em 68/82 hemisférios, o sulco central não atingiu o ramo posterior do sulco lateral. Uma dilatação na segunda curva do giro precentral foi encontrada em apenas 64/82 hemisférios. Conclusão: Os dados morfométricos apresentados neste artigo podem ser úteis como método suplementar para identificação dos reparos anatômicos na região do sulco central.

Palavras-chave: sinal do ômega, sulco central, anatomia, córtex motor primário.

Is the omega sign a reliable landmark for the neurosurgical team? An anatomical study about the central sulcus region

The central sulcus region, which consists of the precentral sulcus, precentral gyrus, central sulcus, postcentral gyrus, and postcentral sulcus, is an eloquent area situated between the frontal and parietal lobes. Cortical maps obtained with direct electrical stimulation ${ }^{1}$ and functional magnetic resonance imaging studies ${ }^{2}$ showed almost identical functional maps, and both methods demonstrated that the motor hand area is located in the superior part of the precentral gyrus ${ }^{1}$ and in a knob on the precentral gyrus ${ }^{2}$.
Several methods have been created to aid both neurosurgeons and neuroradiologists in precisely localizing the precentral gyrus. One of them consists of recognizing the intersection between the superior frontal sulcus and the precentral sulcus, being the motor hand area at the same sagittal plane on the precentral gyrus ${ }^{3,4}$. Another one is localizing the precentral knob, which can be recognized on the axial plane by the form of the Greek letter inverted omega ${ }^{2}$.

The omega sign is a usual way to describe the knob on the precentral gyrus, which represents the motor hand area ${ }^{5}$.

\footnotetext{
${ }^{1}$ Universidade Federal de São Paulo, Departamento de Neurologia e Neurocirurgia, Sao Paulo SP, Brazil;

${ }^{2}$ Hospital Albert Einstein, Departamento de Radiologia, Sao Paulo SP, Brazil;

${ }^{3}$ Universidade Federal de São Paulo, Departamento de Neurocirurgia, Sao Paulo SP, Brazil;

«Universidade Federal de São Paulo, Sao Paulo SP, Brazil;

${ }^{5}$ Instituto de Ciências Neurológicas - ICNE, Sao Paulo SP, Brazil.

Correspondence:Thiago Rodrigues; Rua das Camélias, 29 / apto.31; 04048-060 São Paulo SP, Brasil; E-mail:thiagopereirarodrigues@yahoo.com.br Conflict of interest: There is no conflict of interest to declare.

Received 28 April 2015; Received in final form 23 June 2015; Accepted 13 July 2015.
} 
During direct cortical observation, it is sometimes difficult to understand the cortical anatomy of the sulci and gyrus because of the arachnoid matter ${ }^{6,7}$. Further, anatomical variation often occurs in this region ${ }^{8}$. Therefore, it is important to the neurosurgical team to have many methods, including morphological and morphometric methods, to recognize the sulcal and gyral anatomy of this region.

\section{METHOD}

We analyzed 82 human brain hemispheres obtained from the neuroanatomy laboratory of the Federal University of São Paulo. All of them were preserved in $10 \%$ formalin solution. We removed the arachnoid membranes and dissected the central sulcus region of each one using a surgical microscope (KAPS model SOM 82, Germany). A detailed protocol for analyzing each hemisphere was followed; the same individual analyzed all the samples. The focus was to study the sulci and gyrus of the central sulcus region including its morphological and morphometric aspects. We have also completed a review of the literature on the central sulcus and omega sign anatomy.

\section{RESULTS}

After removing the arachnoid membranes, we were able to characterize the central sulcus in all hemispheres. In all hemispheres analyzed, we observed that the central sulcus had three main curves. The first and third curves were anteriorly convex; the second curve was posteriorly convex.

In 5/82 hemispheres, we found a discontinuation in the central sulcus due to a focal abrupt reduction in the sulci depth, creating an edge-like aspect in the lateral view of the cerebral hemisphere.

Among the 82 hemispheres, the central sulcus did not reach the posterior ramus of the lateral sulcus in 68 specimens, allowing the subcentral gyrus to be visualized in the lateral aspect of the cerebral hemisphere. In the remaining 14 hemispheres, the central sulcus reached the posterior ramus of the lateral sulcus. However, even in these specimens, we could reliably observe a gyrus connecting the inferior aspects of the precentral and the postcentral gyrus in the opercular cleft of the sylvian fissure (Figure 1).

In 63/82 specimens, we visualized an isolated central sulcus, which did not communicate with any other sulcus. In $14 / 82$ specimens, a ramus of the precentral sulcus reached the central sulcus, and in the other $5 / 82$ specimens, a ramus of the postcentral sulcus connected with the central sulcus. However, in the 19 of the 82 hemispheres in which a ramus reached the central sulcus, only a superficial connection was found. In those hemispheres, when we looked at the depth of the sulcus intersection, there was a cortical edge separating the central sulcus from the rami of the precentral and the postcentral sulcus (Figure 2).

A knob on the second curve of the precentral gyrus was reliably identified only in 64/82 hemispheres. This knob had almost the same morphometric aspects in both sided hemispheres (Table).

We also found that the second curve of the central sulcus, which was in apposition with the knob of the precentral gyrus, was located in the projection of the superior frontal sulcus. In a majority of the specimens (76/84), the superior frontal sulcus reached the precentral sulcus, creating an intersectional point which was the invagination base of the second curve of the central sulcus (Figure 3).

\section{DISCUSSION}

It would be important to neurosurgical team to know alternative morphological and morphometric methods to precisely localize the structures of central sulcus region. Taking this point into consideration, the main objective of

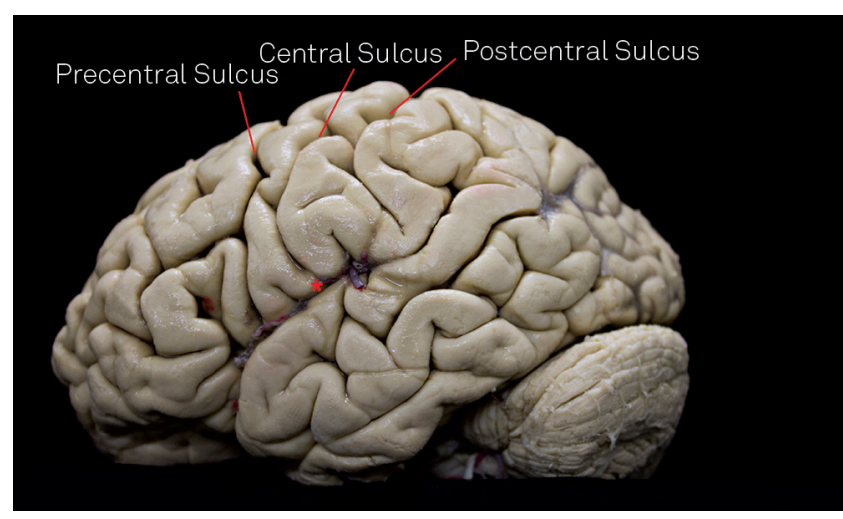

Figure 1. We expose the central sulcus region showing that the central sulcus is separated from the posterior ramus of the lateral sulcus by the subcentral gyrus ${ }^{*}$ ) (pli de passage frontoparietal inferieur).

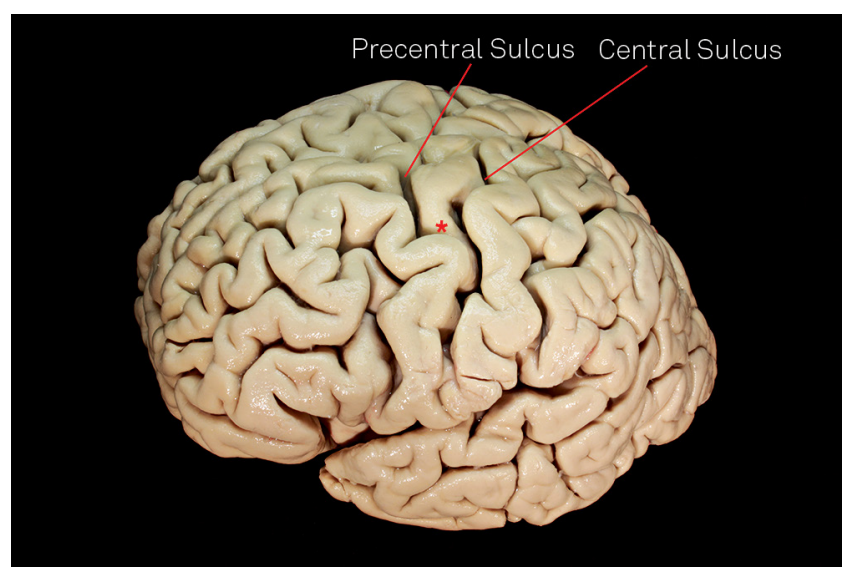

Figure 2. Note a superficial ramus of the precentral sulcus achieving the central sulcus. 
Table. Morphometric evaluation of the Omega Sign in 64 Hemispheres.

\begin{tabular}{|c|c|c|c|c|c|c|c|c|}
\hline & \multicolumn{2}{|c|}{ Omega height (millimeters) } & \multicolumn{2}{|c|}{ Omega width (millimeters) } & \multicolumn{2}{|c|}{$\begin{array}{l}\text { Distance to medial edge of the } \\
\text { hemisphere (millimeters) }\end{array}$} & \multicolumn{2}{|c|}{$\begin{array}{c}\text { Distance to posterior ramus of } \\
\text { lateral sulcus (millimeters) }\end{array}$} \\
\hline & Right (34 h) & Left (30 h) & Right (34 h) & Left $(30 \mathrm{~h})$ & Right (34 h) & Left (30 h) & Right (34 h) & Left (30 h) \\
\hline Average & 6.588 & 6.4 & 17.82 & 17.5 & 20.617 & 18.633 & 41.529 & 41.166 \\
\hline Max & 12 & 14 & 25 & 25 & 37 & 32 & 70 & 50 \\
\hline Min & 3 & 3 & 10 & 12 & 7 & 7 & 20 & 30 \\
\hline S.D. & 2.105 & 2.54 & 4.323 & 3.866 & 8.842 & 6.774 & 10.272 & 5.583 \\
\hline
\end{tabular}

SD: standard deviation; $h$ : hemispheres.

this study was to better characterize the central sulcus region. Direct cortical stimulation studies ${ }^{1,9}$ and recent functional magnetic resonance imaging studies ${ }^{2}$ have demonstrated that the precentral gyrus lodges the motor primary cortex and the second curvature of the central sulcus, which corresponds to the knob-like form in the precentral gyrus, are specifically associated with contralateral motor hand skills.

We found the knob on the precentral gyrus, which represents the motor hand area, in 64/82 hemispheres. Even after removing all the arachnoid membranes, we could not identify the motor hand area in 18/82 hemispheres using direct cortical inspection.

As demonstrated in the Table, the average distance of the knob on the precentral gyrus to medial edge of the hemisphere was $20.617 \mathrm{~mm}$ and $18.633 \mathrm{~mm}$ on the right and left hemisphere respectively. And the average distance of the knob on the precentral gyrus to the posterior ramus of the lateral sulcus was $41.529 \mathrm{~mm}$ and $41.166 \mathrm{~mm}$ on the right and left hemisphere respectively. This morphometric data can be applied as an alternative method to localize the motor hand area on the precentral gyrus.

The knob on the precentral gyrus is mainly formed by two sulci perpendicular to the central sulcus (Figure 4). These sulci are more highly accentuated at deeper levels of the central sulcus and become smooth or even disappear at the cortical level of the central sulcus. The sulcal configuration of this region can explain the fact that sometimes the knob on the precentral gyrus cannot be observed by direct cortical visualization.

Furthermore, even with evident axial imaging showing the omega sign, we could not always find the knob on the precentral gyrus. Therefore, we think that morphometric data such as distance of the knob to the medial edge of the hemisphere or to the posterior ramus of the lateral sulcus can be useful in this case.

The focal abrupt reduction of the central sulcus depth that was found in $5 / 82$ hemispheres probably corresponds to the pli de passage fronto-pariétal moyen (PPFM) described by Broca ${ }^{10,11}$. Actually, a study using 3-dimensional reconstruction of the central sulcus showed the PPFM in $96.4 \%$ and $89.1 \%$ in the left and right hemispheres, respectively ${ }^{12}$. This divergent result was probably because we were only able to visualize the PPFM large enough to be observed in the lateral aspect of cerebral hemispheres.

The pli de passage frontoparietal inferieur ${ }^{11}$, which corresponds to the subcentral gyrus, could be seen in all hemispheres.

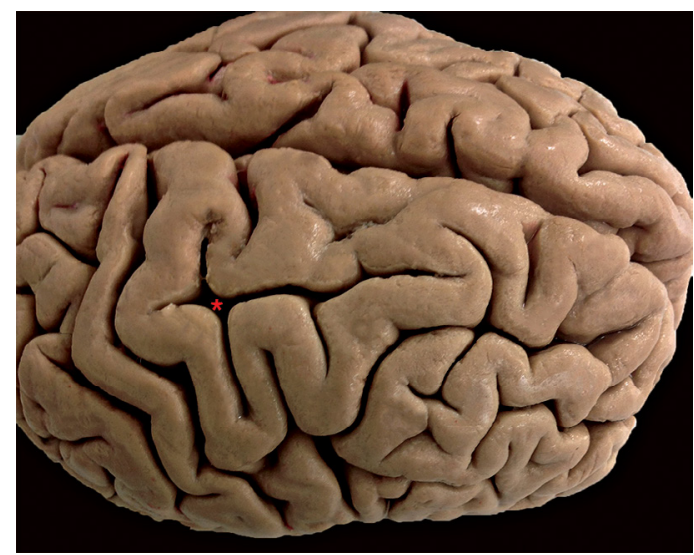

Figure 3. The intersectional point between the superior frontal sulcus and precentral sulcus (*) is the invagination base of the knob on the precentral gyrus.

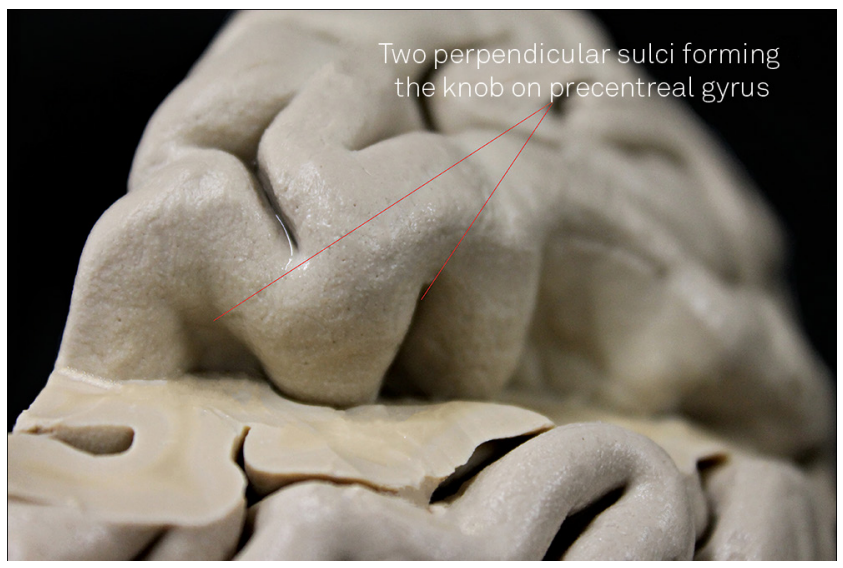

Figure 4. We remove the postcentral gyrus to expose the central sulcus bottom. There are 2 perpendicular sulci which form the omega sign. These sulci are more accentuated at deeper levels of the central sulcus.

In recent years, the multimodal intraoperative monitoring has become more often used. It generally consists in three main modalities, when dealing with central sulcus lesions, which are the following: direct cortical stimulation, phase reversal technique and the subcortical stimulation ${ }^{13}$.

Direct cortical stimulation is made with a directly electrical stimulus applied on the cerebral cortex. Commonly is used monopolar or bipolar stimulus and electromyographic recording to construct a cortical map in the precentral gyrus ${ }^{13}$. 
The phase reversal technique is a method to identify the central sulcus using the median nerve somatosensory evoked potential. An electrocorticography strip crossing the central sulcus shows an initially downward deflection anterior to central sulcus and an initially upward deflection posterior to central sulcus $20-\mathrm{ms}$ after a median nerve stimulus ${ }^{14}$.

The subcortical stimulation can be used in the central sulcus region to evaluate the proximity of the corticospinal tract. In the same way as direct cortical stimulation, a bipolar stimulus is applied in the subcortical region and an electromyographic change is recorded ${ }^{15}$.

In our opinion, a combination of anatomical landmarks and morphometrical measures with the multimodality intraoperative monitoring is important to deal safely with central sulcus lesion.

\section{Example Case}

A thirty years old woman with history of focal seizure was admitted at our institution. Initial radiological evaluation showed a left frontal lesion closely located to central sulcus region (Figure 5). She was submitted to microsurgical resection of the lesion using intraoperative multimodal monitoring method associated with anatomical localization. (Figure 6 and 7). The anatomopathologic findings were compatible with diffuse astrocytoma. She improved her seizure symptoms, had no additional neurological deficit and is being accompanied on ambulatory care unit.

In conclusion, the morphometric data presented in this article can be useful as supplementary method to identify the central sulcus region landmarks.
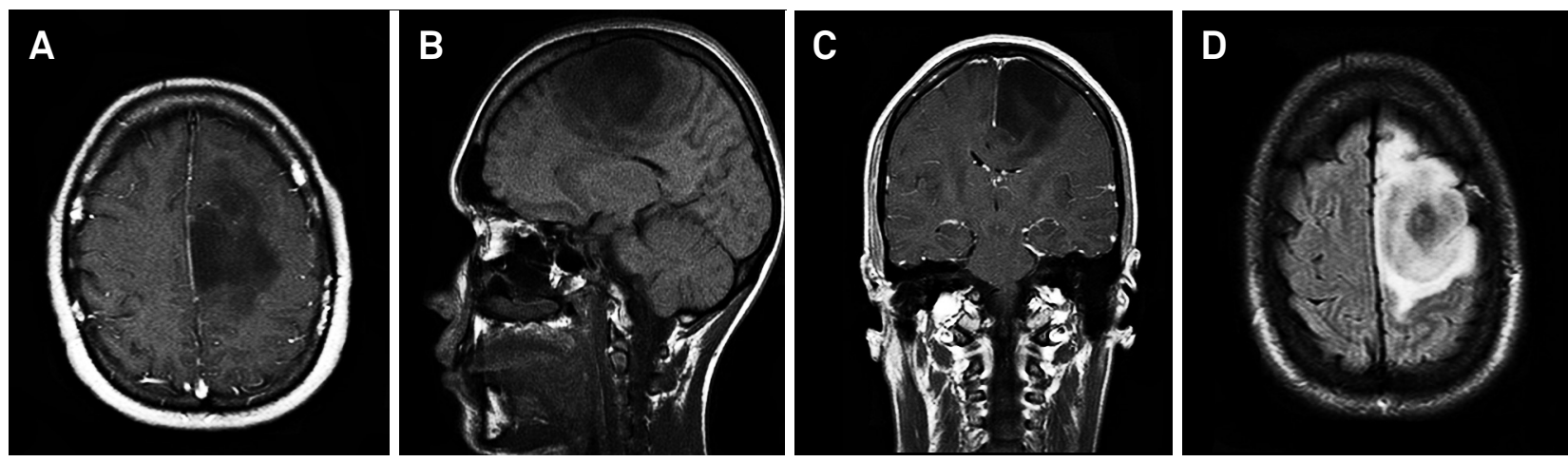

Figure 5. Magnetic resonance image on T1W in axial (A), sagittal (B), coronal (C) and FLAIR (D) shows a non-enhancing lesion centered at the junction between frontal superior gyrus and the precentral gyrus.
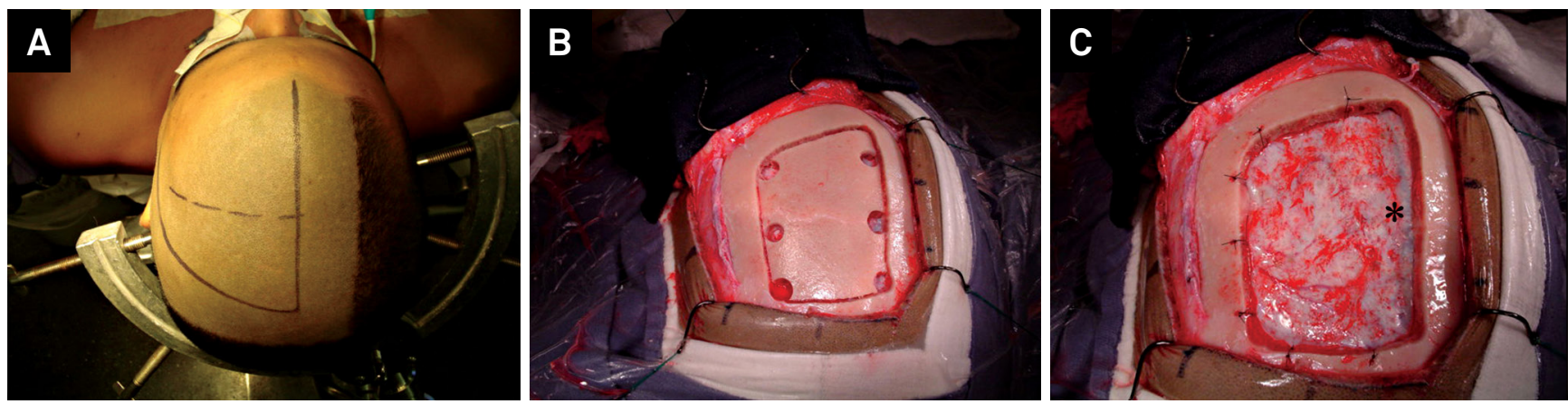

Figure 6. (A) The dotted line is marking the coronal suture and the continuous line delimits the skin incision. (B) Bone flap after the craniotomy. (C) Dural exposure showing the superior sagittal sinus in the medial edge of the craniotomy $(*)$.
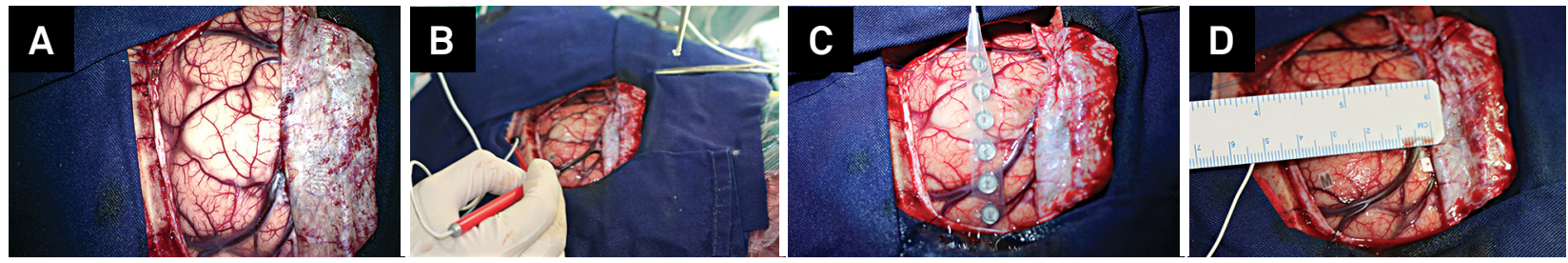

Figure 7. (A) Left frontoparietal craniotomy exposing the medial edge of the left hemisphere demonstrated the lesion in the center of the figure. (B) Direct cortical monopolar stimulation is used to localize motor eloquent areas. (C) The phase reversal method using a strip crossing the central sulcus indicated the central sulcus between the distal first and the distal second electrode. (D) The letter "M" on the precentral gyrus marque the motor hand area and is located about $3,2 \mathrm{~cm}$ of the medial edge of the hemisphere. 
1. Penfield W, Boldrey E. Somatic motor and sensory representation in the cerebral cortex of man as studied by electrical stimulation. Brain. 1937;60(4):389-443. doi:10.1093/brain/60.4.389

2. Yousry TA, Schmid UD, Alkadhi H, Schmidt D, Peraud A, Buettner A et al. Localization of the motor hand area to a knob on the precentral gyrus: a new landmark. Brain. 1997;120(1):141-57. doi:10.1093/brain/120.1.141

3. Ebeling U, Steinmetz H, Huang YX, Kahn T. Topography and identification of the inferior precentral sulcus in MR imaging. AJR Am J Roentgenol. 1989;153(5):1051-6. doi:10.2214/ajr.153.5.1051

4. Kido DK, LeMay M, Levinson AW, Benson WE. Computed tomographic localization of the precentral gyrus. Radiology. 1980;135(2):373-7. doi:10.1148/radiology.135.2.7367629

5. Campero A, Ajler P, Martins C, Emmerich J, Alencastro LF, Rhoton A. Usefulness of the contralateral Omega sign for the topographic location of lesions in and around the central sulcus. Surg Neurol Int. 2011;2(1):164. doi:10.4103/2152-7806.89892

6. Rodrigues TP, Rodrigues MAS, Paz DA, Costa MD, Centeno RS, Chaddad Neto FE et al. Orbitofrontal sucal an gyrus pattern in human: an anatomical study. Arq Neuropsiquiatr. 2015;75(5):431-44. doi:10.1590/0004-282X20150048

7. Chaddad Neto FE, Joaquim AF, Santos MJ, Linhares PW, Oliveira E. Microsurgical approach of arteriovenous malformations in the central lobule. Arq Neuropsiquiatr. 2008;66(4):872-5. doi:10.1590/S0004-282X2008000600018
8. Ono M, Kubik S, Abernathey CD. Atlas of cerebral sulci. Stuttgart: Thieme; 1990.

9. Penfield W, Rasmussen T. The cerebral cortex of the man. New York: Macmillan; 1950.

10. Alkadhi H, Kollias SS. Pli de passage fronto-pariétal moyen of Broca separates the motor homunculus. AJNR Am J Neuroradiol. 2004;25(5):809-12.

11. Broca P. Memoires d'anthropologie. Paris: Reinwald; 1888.

12. Cykowski MD, Coulon O, Kochunov PV, Amunts K, Lancaster JL, Laird AR et al. The central sulcus: an observer-independent characterization of sulcal landmarks and depth asymmetry. Cereb Cortex. 2008;18(9):1999-2009. doi:10.1093/cercor/bhm224

13. González-Darder JM, González-López P, Talamantes F, Quilis V, Cortês V, Garcia-March G, et al. Multimodal navigation in the functional microsurgical resection of intrinsic brain tumors located in eloquent motor areas: role of tractography. Neurosurg Focus. 2010;28(2):E5. doi:10.3171/2009.11.FOCUS09234

14. Sheth SA, Eckhardt CA, Walcott BP, Eskandar EN, Simon MV. Factors affecting successful localization of the central sulcus using the somatosensory evoked potential phase reversal technique. Neurosurgery. 2013;72(5):828-34. doi:10.1227/NEU.0b013e3182897447

15. Shiban E, Krieg SM, Haller B, Buchmann N, Obermueller T, Boeckh-Behrens T, et al. Intraoperative subcortical motor evoked potential stimulation: how close is the corticospinal tract?. J Neurosurg. 2015;5:1-10. 